\title{
Foundations of a Framework to Evaluate Impacts on Future Noise Situations at Airports
}

\author{
Felix Will ${ }^{1}$ \\ Technical University of Munich, 85748 Garching, Germany \\ Christoph Engelke ${ }^{2}$ \\ Technical University of Munich, 85748 Garching, Germany \\ Tim-Oliver Wunderlich ${ }^{3}$ \\ Technical University of Munich, 85748 Garching, Germany \\ Mirko Hornung ${ }^{4}$ \\ Technical University of Munich, 85748 Garching, Germany
}

\begin{abstract}
Noise emissions in the vicinity of airports are a major challenge regarding the future of aviation. In this work we present the development of a framework to assess the impacts on future noise situations at the multi-event level. The framework at its top-level consists of three main areas: Modeling future airport flight plans, modeling aircraft noise at the vehicle level, and modeling aircraft noise at the airport level, which makes use of the Aviation Environmental Design Tool (AEDT). This paper focuses on airport flight plan modeling that derives future flight plans from a given flight plan considering user-specific scenario input. Therein, firstly, air traffic growth is considered. Secondly, the retirement of aircraft is considered by analyzing the age distribution of the current world aircraft fleet and by applying retirement curves for nine aircraft clusters. Thirdly, aircraft introduction is considered allowing for the precise definition of aircraft fleet composition to enter the fleet in future years. Fourthly, a simple capacity module considers airport capacity constraints. The framework does not aim at forecasting actual future flight plans or absolute noise levels, but aims for relative scenario comparisons for the purpose of impact assessments. A use case applies the developed flight plan model to Munich Airport.
\end{abstract}

\section{Nomenclature}

$\begin{array}{ll}A / C & =\text { Aircraft } \\ A E D T & =\text { Aviation Environmental Design Tool } \\ A S & =\text { Available Seats } \\ C T & =\text { Current Technology } \\ D E N & =\text { Day-Evening-Night } \\ F A N A M & =\text { Future Airport Noise Impact Assessment Method } \\ F F D T & =\text { Future Flight Plan Development Tool } \\ I N M & =\text { Integrated Noise Model } \\ N B & =\text { Narrow-Body } \\ N T-1 /-2 & =\text { New Technology } 1^{\text {st }} / 2^{\text {nd }} \text { Generation } \\ O E M & =\text { Original Equipment Manufacturer } \\ S I D & =\text { Standard Instrument Departure } \\ W B & =\text { Wide-Body }\end{array}$

\footnotetext{
${ }^{1}$ Research Assistant, Institute of Aircraft Design, Boltzmannstrasse 15, AIAA Student Member.

${ }^{2}$ Graduate Student, Institute of Aircraft Design, Boltzmannstrasse 15.

${ }^{3}$ Graduate Student, Institute of Aircraft Design, Boltzmannstrasse 15.

${ }^{4}$ Professor, Institute of Aircraft Design, Boltzmannstrasse 15, AIAA Senior Member.
} 


\section{Topic Motivation}

ircraft noise is a main challenge for the future of civil aviation. At the global level, carbon dioxide emissions can be regarded as the main environmental impact by aviation. However, at a local level, noise emissions in the vicinity of airports are arguably the environmental impact perceived most strongly by residents.

During recent years, a significant amount of research has been undertaken in order to better understand and minimize aircraft noise emissions. In this, research with respect to aviation noise is conducted at different system levels. First of all, much research has been done in order to reduce aircraft source noise at the aircraft component level. As result of engine noise research, engine noise emission has declined strongly over the last decades. Other research efforts at the aircraft component level target airframe noise aiming at a reduction of noise from non-engine sources, for instance, landing gears or high-lift devices ${ }^{1}$.

Besides source noise reduction of aircraft components, research is also done at the aircraft level. At the aircraft level, noise research either aims at a reduction of noise emission through aircraft design, for example, through unconventional aircraft configurations, or at operational noise abatement procedures with a given aircraft configuration.

Aircraft noise research targeting aircraft design, for instance, places engines above the wings in over-wing-nacelle configurations in order to decrease the noise impact on the ground through noise shielding effects ${ }^{2}$. More radical configurations put aside the traditional tube-and-wing configuration, e.g. striving for blended-wing-body concepts that strongly benefit from noise shielding when engines are placed above the wing ${ }^{3}$.

Research concerning operational noise abatement procedures aims at improved flight procedures applied to a given aircraft in order to minimize the noise impact on residents of airports. For example, research has been done aiming at continuous descend operations that reduce noise on the ground through lower engine power settings, resulting in decreased source noise, and increased distance between aircraft and ground ${ }^{4}$.

Both research in source noise reduction, be it at the component or aircraft level, and operational noise abatement procedures are often assessed for single events, that is, for a single flight operation. However, for residents of airports, cumulated noise situations over longer periods of time are of primary interest. Thus, for residents multi-event assessments at the airport level are more relevant than single-event assessments. Policy makers, for instance, follow this by considering aircraft noise not only for single flight events, but also for cumulative periods, e.g. by regarding equivalent continuous sound levels 5 .

At the airport level, for example, a modeling approach to examine the effect of vehicle-level technology impact on airport noise contours has been developed ${ }^{6}$. A recent study introduces a model for the rapid assessment of future aviation noise near airports and compares the model with the Integrated Noise Model (INM) ${ }^{7}$. The framework developed in this research is devoted to the assessment of aircraft noise at the airport level and aims at an enhanced understanding of impacts on future noise situations. It develops a method that is able to evaluate different impacts on future noise situations at airports, for instance, reduced noise emission in future aircraft types, the impact of air traffic growth, or the impact of future aircraft fleet mixes. The foundations of the developed framework are introduced in the following.

\section{Top-Level Approach of the Framework}

The developed framework is named the Future Airport Noise Impact Assessment Method (FANAM). The top-level approach of FANAM is presented in Figure 1. As shown in the figure, assessing the fundamental impacts on future airport-level noise situations at its basis requires three systems to be modeled. Firstly, a flight plan at the airport under consideration is needed and is to be modeled for future years. Secondly, aircraft noise of all relevant aircraft types is to be modeled at aircraft level. Thirdly, from the flight plan and individual aircraft models, aircraft noise needs to be modeled at airport level. In order to be applicable to FANAM, the three models must be able to interact through defined interfaces. Since the scope of the presented research is quite comprehensive, all three

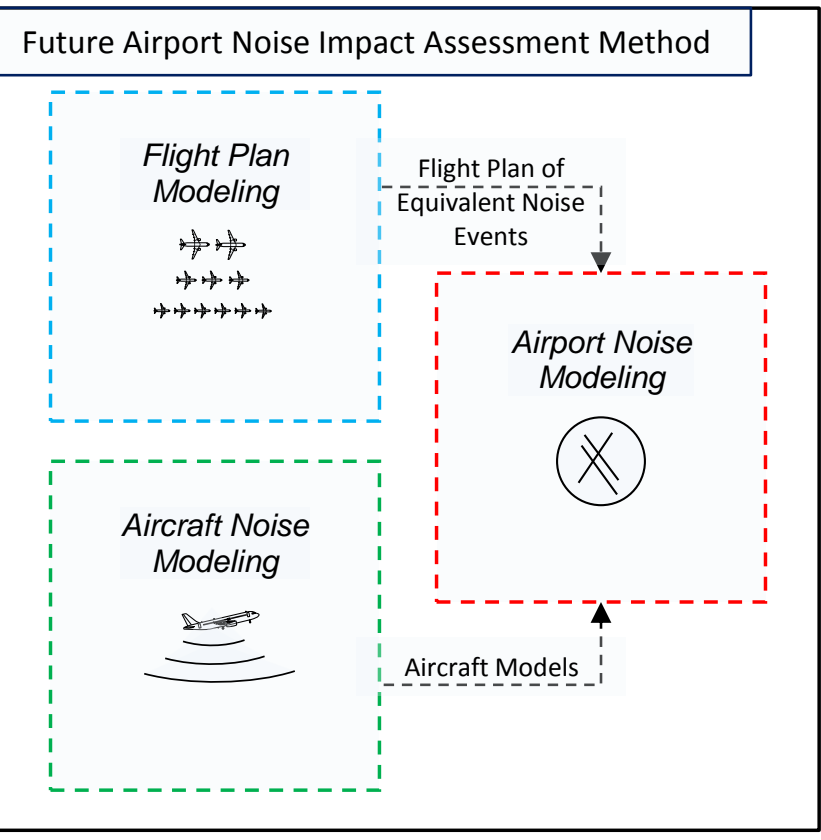

Figure 1. Top-Level Approach of the Framework 
systems to be modeled require assumptions that correspond to the overall objective of the framework. Future noise situations are analyzed by Day-Evening-Night (DEN) levels as a result of the airport noise modeling capabilities. The framework is implemented in MATLAB ${ }^{\circledR}$.

To allow for a precise description of aircraft technology generations three different categories of aircraft technology are defined:

1. Current technology aircraft (CT): Aircraft types that are already in service in the world fleet at the time of the base year. The base year is the reference year that future flight plans will be derived from. In this study, the base year is defined as 2014. Examples of CT aircraft types are the Airbus A320 or Boeing 737. The base fleet is the aircraft fleet from the base year and consequently only includes CT aircraft types. A base flight plan is a flight plan from the base year.

2. New technology $1^{\text {st }}$ generation aircraft (NT-1): New aircraft types that enter the world fleet only in the base year or within the following few years; thus aircraft types that are in a final design, certification or near entry-into-service phase in the base year. Examples of NT-1 aircraft types are the Airbus A320neo or Boeing 787-9.

3. New technology $2^{\text {nd }}$ generation aircraft (NT-2): New aircraft types that, during the base year, are years away from market readiness; aircraft types that cannot be ordered at the time of the base year.

Furthermore, aircraft types are categorized by their tube category into Narrow-Body (NB, single-aisle) and WideBody (WB, twin-aisle) aircraft. This paper focuses on the development of the flight plan modeling capabilities, the first system to be modeled within FANAM, as seen in Figure 1. The approach of flight plan modeling is presented in the following chapter.

\section{Flight Plan Modeling}

\section{A. Overall Approach of the Flight Plan Model}

Future flight plans are one of the three top-level systems to be modeled within FANAM (see Figure 1). For a specific airport to be assessed, the objective of the flight plan modeling is to derive future flight plans at a level of detail appropriate for the assessment of impacts on future airport noise situations.

The developed method for flight plan modeling is called the Future Flight Plan Development Tool (FFDT). The fundamental approach of the FFDT is outlined in Figure 2. From a given flight plan from the base year, a future flight plan is modeled through several processing steps. Since for FANAM only noise-relevant information contained in a flight plan are relevant, the FFDT uses so-called Flight Plans of Equivalent Noise Events. In such a flight plan, flight operations with equivalent noise characteristics are consolidated as further detailed in Section B.

As presented in Figure 2, from the flight plan of the base year, the FFDT considers changes resulting from air traffic growth and aircraft retirement on the future flight plan. Air traffic growth is modeled by the application of userspecified growth data as detailed in Section C. Aircraft retirement is modeled using aircraft-specific retirement curves as presented in Section D.

From air traffic growth and aircraft retirement, a flight plan gap is calculated as detailed in Section E. The flight plan gap represents air traffic demand that cannot be met by a current aircraft fleet, causing new aircraft to enter the fleet. The aircraft introduction module specifies which aircraft type(s) replace(s) a certain retired aircraft type. The user of the FFDT may specify precise introduction rules as described in Section F. Applying the air traffic growth

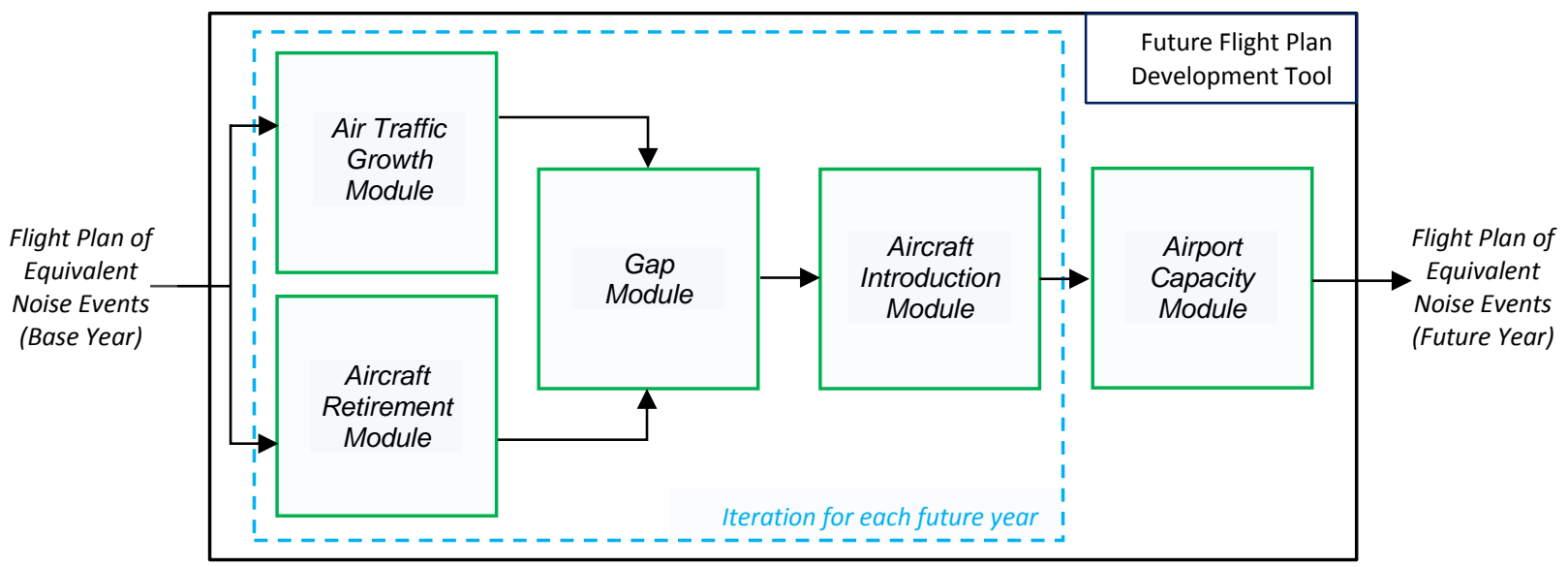

Figure 2. Approach of the Future Flight Plan Development Tool (FFDT)

American Institute of Aeronautics and Astronautics 
module, the aircraft retirement module, the gap module, and the aircraft introduction module, flight plans are iteratively calculated for each future year.

Since many of today's airports facing noise challenges operate close to their maximum capacity, a simple airport capacity module shifts flight operations exceeding the actual hourly capacity limit to neighboring, less frequented hours of the day as specified in Section G. The module thus accounts for possible shifts from day-time operations to evening or night-time operations and resulting implications on calculated DEN-levels due to noise penalties for nonday-time operations. The result of the FFDT is a Flight Plan of Equivalent Noise Events for a selected future year. Flight plans derived by the FFDT may then be used for future airport-level noise studies within FANAM.

The presented method expresses air traffic growth at a passenger transport-level rather than at an aircraft movement-level. Thus, instead of directly modeling numbers of future aircraft operations, e.g. on a specific flight route, the method uses transport capacity to model future years. This is crucial in order to account for the effect of increasing aircraft seat capacity in future fleets.

\section{B. Structure and Development of the 'Flight Plan of Equivalent Noise Events'}

The description of aircraft operations at the airport is based on a flight plan from $\mathrm{OAG}^{8}$ during the base year. Since the OAG flight plan format contains data at a detailed level, a new structure of flight plan is derived that is specifically tailored to airport noise assessments and consolidates all noise-equivalent flight operations. Such a flight plan is called a Flight Plan of Equivalent Noise Events. An exemplary Flight Plan of Equivalent Noise Events for departure operations is presented in Table 1 and explained in the following. The Flight Plan of Equivalent Noise Events for approach operations applies the analogous rationale excluding weight-specific information.

Each flight plan entry, that is, each row of Table 1, summarizes the scheduled flights of one year that share equivalent noise characteristics. Equivalent noise characteristics are given if aircraft operations share the same hour of day, the same destination airport, and the same aircraft type. These three parameters are called primary flight plan parameters.

The hour of day (in hourly intervals) of an operation is relevant to noise due to possible evening or night penalties when calculating DEN-levels. DEN-levels require the assignment of an operation to one of the three intervals 'day', 'evening', or 'night'. However, the capacity module (see Figure 2) uses more detailed information with respect to the hour of day, thus operations are assigned to hourly intervals. The destination airport (IATA code) determines several noise-relevant parameters: Firstly, the destination determines aircraft weight at departure (as a function of distance or stage length) which interferes with the vertical operational profile of the aircraft movement. Secondly, it impacts the departure route of an operation, which determines the horizontal and vertical operational profile of the aircraft movement. An airport's direction of operation is determined by the wind. A yearly average of wind distribution is used to assign flight operations to the possible operation directions of a runway system. Thirdly, the destination airport determines destination-specific future air traffic growth by linking destinations to region routes (see Chapter II.B). Although this is not relevant for the noise calculation itself, it is necessary to link the region-specific air traffic growth to specific aircraft movements when calculating future flight plans with the FFDT. At last, the noise emission of an operation depends on the specific noise characteristics of the aircraft type (IATA code). In this, the method FANAM does not substitute aircraft by representative aircraft types, e.g. to reduce the amount of modeled aircraft types, but takes into account specific aircraft types.

The primary flight plan parameters fully define further secondary flight plan parameters relevant for future airport noise assessments and used with FANAM as seen in Table 1: The period of day (day/evening/night) used by the capacity module is defined by the hour of the day. The region route necessary for region-specific air traffic growth, the stage length determining departure weight, and the departure route determined by the corresponding Standard Instrument Departure (SID) waypoint defining the particular SID for departures are defined by the destination airport.

Table 1. Extract of a Flight Plan of Equivalent Noise Events for departure operations. Primary flight plan parameters in light grey, secondary in dark grey.

\begin{tabular}{|c|c|c|c|c|c|c|c|c|}
\hline $\begin{array}{c}\text { Hour of } \\
\text { Day }\end{array}$ & $\begin{array}{c}\text { Period of } \\
\text { Day }\end{array}$ & $\begin{array}{c}\text { Desti- } \\
\text { nation } \\
\text { Airport }\end{array}$ & $\begin{array}{c}\text { Region } \\
\text { Route }\end{array}$ & $\begin{array}{c}\text { Stage } \\
\text { Length }\end{array}$ & $\begin{array}{c}\text { Departure } \\
\text { Route }\end{array}$ & $\begin{array}{c}\text { Aircraft } \\
\text { Type }\end{array}$ & $\begin{array}{c}\text { Transport } \\
\text { Capacity } \\
\text { in AS) }\end{array}$ & $\begin{array}{c}\text { Frequ- } \\
\text { encies }\end{array}$ \\
\hline $6: 00$ & 'D' & 'ACE' & $\begin{array}{l}\text { 'Western } \\
\text { Europe' }\end{array}$ & 3 & 'ALG' & 320 & 1620 & 0.0247 \\
\hline $6: 00$ & 'D' & 'ACE' & $\begin{array}{c}\text { 'Western } \\
\text { Europe' }\end{array}$ & 3 & 'ALG' & 738 & 1488 & 0.0219 \\
\hline
\end{tabular}


One flight plan entry then specifies the transport capacity by the amount of Available Seats (AS) of all noiseequivalent flight operations of one year. For the application of flight plans to the airport noise model, numbers of operations are derived from the transport capacity by considering aircraft-individual seat capacity numbers. The amount of operations is specified in frequencies, thus operations per day.

\section{Air Traffic Growth Module}

In order to quantify future airport operations, a model for air traffic growth simulation is required. The presented growth module uses region-pair-based (e.g. 'Western Europe - Latin America') air traffic growth in revenue passenger kilometers (RPK) as input data. RPK growth rates can be applied on transport capacity growth (in AS) accepting the assumption that average flight distance and seat load factor within a region-pair remain constant. Since every flight plan entry contains a destination or origin airport that is assigned to a specific region, corresponding growth rates can be applied to extrapolate the transport capacity of the flight plan entry for future years. The source of region-pairspecific growth data used in the presented method is an open-source-based growth report for the years 2015-2035 from Airbus Global Market Forecast ${ }^{9}$. Therein, air traffic growth is specified for 180 region-pairs. However, for application in the growth module of the FFDT, only those region-pairs are relevant that include the particular airport under consideration. For years beyond 2035, the 2035 growth rates are continued.

\section{Aircraft Retirement Module}

Aircraft retirement is a significant promotional factor for the introduction of new technology aircraft types. Therefore, retirement requires a sophisticated modeling method. The presented method suggests a statistical approach of modeling the retirement behavior of current technology aircraft types based on aircraft cluster-specific retirement curves. Retirement curves are derived from worldwide past retirement behavior data and extrapolated for the future retirement of both CT and NT-1/2 aircraft types. A brief summary of the retirement model is given in the following.

\section{Clustering of Aircraft Types}

The retirement behavior of different aircraft types is modeled at a cluster-level rather than at the individual aircraft type-level. In the presented method, aircraft types are summarized in nine aircraft type clusters shown in Table 2 . The definition of these clusters has been developed by Randt and was used in the context of worldwide fleet modeling in previous research ${ }^{10}$. The clusters are statistically derived to group similar aircraft types using parameters such as aircraft seat capacity, operating distance and propulsion type.

Table 2. Definition of nine aircraft clusters used for retirement modeling according to Randt ${ }^{10}$

\begin{tabular}{|c|c|c|}
\hline Cluster ID & Cluster Name & Exemplary Aircraft Type \\
\hline 1 & Long-Range Combi & Boeing MD-11 \\
\hline 2 & Long-Range Heavy Passenger & Boeing 747-400 \\
\hline 3 & Mid-Range Freighter & Boeing 767-300F \\
\hline 4 & Jet Commuter & Embraer 190 \\
\hline 5 & Long-Range Freighter & Boeing 747-400F \\
\hline 6 & Turboprop Commuter & ATR 72-500 \\
\hline 7 & Mid-Range Passenger & Boeing 767-300 \\
\hline 8 & Long-Range Passenger & Boeing 777-200 \\
\hline 9 & Short/Mid-Range Passenger & Airbus A320 \\
\hline
\end{tabular}

\section{Derivation of Retirement Curves}

Retirement curves have been modeled at cluster-level using a methodology developed by the Forecasting and Economic Analysis Support Group (FESG) of the $\mathrm{ICAO}^{11}$. This methodology derives retirement curve data points by plotting the percentage of aircraft that are still in service (relative to $100 \%$ of aircraft that were built in a specific year) against the age of the specific aircraft lot. The required data are obtained from an open-source worldwide fleet database $^{12}$. To smooth single runaway values that might result from these calculations, data points of the retirement curve plot were used for a regression analysis to develop a best-fit s-shaped retirement curve for each cluster. The resulting cluster-specific retirement curves as derived by Randt are shown in Figure 3.

In order to apply these generic retirement curves to model the future retirement of an existing base fleet the base fleet's age distribution needs to be considered. The age distribution is derived for each individual aircraft type from the same world fleet database used for deriving retirement curves ${ }^{12}$. Combining both aircraft type-specific age distribution and cluster-specific retirement curves allows one to derive retirement factors for individual aircraft types 


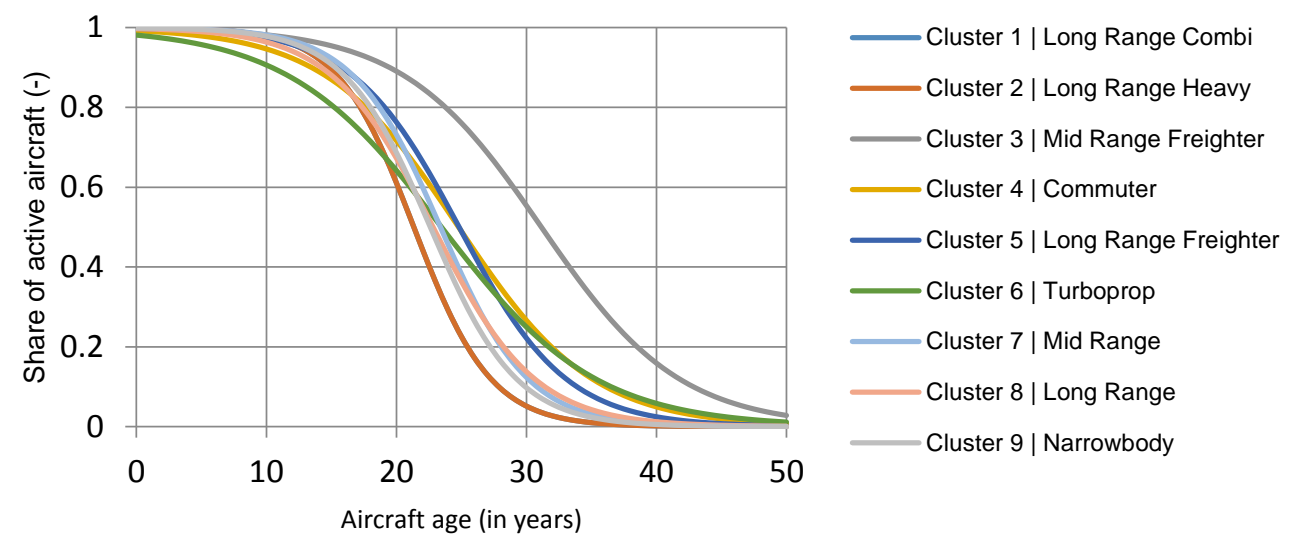

Figure 3. Applied retirement curves for nine aircraft clusters ${ }^{10}$

in the base fleet. We define a retirement factor as the share of aircraft that are still in service in a future year relative to the base year. Retirement factors are used to calculate future transport capacities that were not yet subject to retirement for each flight plan entry of a base fleet aircraft. This is done by multiplying the transport capacity (in AS) in the base year with the future year-specific retirement factor.

Not only retirement of the base fleet but also of aircraft entering service in future simulation years is modeled by the retirement module. However, the age distribution of aircraft that are not part of the base fleet is a dynamic result of each year iteratively simulated by the FFDT. Thus, the static retirement factors of the base fleet cannot be used. For retirement of future aircraft introduced to the fleet, the retirement module applies the cluster-specific retirement curves. NT-1 and NT-2 aircraft entering service are assigned to one of the nine aircraft clusters based on their aircraft category and seat capacity. As opposed to applying static retirement factors as done with the base fleet, the process of modeling retirement of new aircraft is dynamic and iterative for each future year. The retirement of aircraft that is not part of the base fleet is calculated based on its cluster-specific retirement curve considering the age the new aircraft has reached in a specific future year.

\section{E. Gap Module}

Both air traffic growth and retirement of the base fleet aircraft lead to the demand of new aircraft to enter service (see Figure 2). In the presented method, the amount of required new entry into services is defined by calculating a gap of transport capacity (in AS) for each flight plan entry for each future year. This gap is derived by subtracting the transport capacity of a previous year's base fleet after retirement from the modeled transport capacity of the considered year. Equation (1) shows the calculation of a flight plan gap $G$ (in AS) of a flight plan entry $i$ for the year $t+1$. Therein, $A S$ represents the transport capacity of the previous year $t, g$ describes the regionpair-specific growth factor, and $r$ expresses the aircraft type-specific retirement factor.

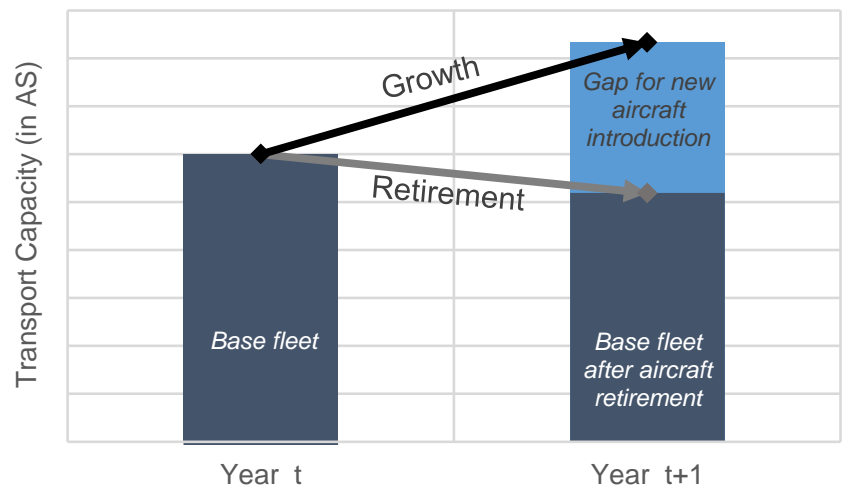

Figure 4. Interaction of air traffic growth and aircraft retirement causing a flight plan gap

$$
G_{i, t+1}=A S_{i, t} *\left(1+g_{i, t+1}\right)-A S_{i, t} *\left(1-r_{i, t+1}\right)
$$

Figure 4 visualizes an exemplary flight plan entry that experiences growth for the year $t+1$ relative to year $t$. At the same time, the base fleet of year $t$ experiences a partial retirement based on the retirement modeling. Consequently, a gap of transport capacity for that flight plan entry results. This gap is filled by introducing new aircraft to the fleet as presented in the following section. 


\section{F. Aircraft Introduction Module}

The future aircraft fleet composition influences future airport noise situations and thus is of interest for impact assessments. In general, the future aircraft fleet is composed of base fleet aircraft and of new aircraft introduced to the fleet in future years. The aircraft introduction module considers the introduction of new aircraft to the fleet. Therein, the goal of the module is to enable FANAM to assess the impact of differing aircraft introduction scenarios on future airport noise. The purpose of the module thus is not to predict the precise composition of new aircraft entering the fleet that, at a specific airport, strongly depends on individual airlines' fleet strategies. Consequently, the module allows FANAM to define precise rules for aircraft introduction as user-defined scenario input.

Within the FFDT, new aircraft are introduced to the fleet as a result of flight plan gaps caused by aircraft retirement and air traffic growth (see Figure 4). For each flight plan entry of the base flight plan the aircraft introduction module interprets the calculated gap as required additional transport capacity that demands the introduction of new aircraft to the fleet. The module principally allows for the substitution of CT aircraft types with CT, NT-1, or NT-2 aircraft types. For each future year and each flight plan entry, the module allocates the flight plan gap to either one or a mix of new aircraft types to enter service.

The aircraft introduction module uses the concept of year-specific swap factors. For a future year, a swap factor defines the share in transport capacity gap of a flight plan entry that is filled by a particular aircraft type entering service. Swap factors describe introduction rules such as the following example: In the year 2017 a flight plan gap of 1 AS of Airbus A320 is replaced with 20\% Airbus A320 (CT), 40\% Airbus A320neo (NT-1), and 40\% Airbus A321neo (NT-1). The yearly swap factors of all aircraft types are aggregated in a so-called swap matrix as depicted in Figure 5 on the right.

In the introduction of aircraft, it is assumed that wide-body aircraft are always replaced by wide-body aircraft and narrow-body aircraft are always replaced by narrow-body aircraft. This assumption is supported by analysis performed on airline press releases concerning airline fleet strategies.

In the introduction module, swap factors are derived using a concept of macro-swap factors and micro-swap factors. On the one hand, macro-swap factors define the share of technology generation (CT, NT-1, NT-2) to be introduced to the fleet. They therefore serve to steer the introduction of more modern versus older aircraft types. For example, a macro-swap factor set of 0\% CT, 100\% NT-1, and 0\% NT-2 exclusively defines NT-1 aircraft types to be commissioned. On the other hand, micro-swap factors define the share of particular aircraft types to be introduced to the fleet within one technology generation (CT, NT-1, NT-2) and tube category (NB, WB).

Figure 5 visualizes the determination of macro-swap factors, micro-swap factors, and the resulting swap matrix. The figure only exemplarily presents two narrow-body aircraft types to be replaced (Airbus A320 and Boeing 737) and four aircraft types available for introduction.

Firstly, scenario-specific macro-swap factors are defined for each future year, as seen in Figure 5 on the top left. Secondly, micro-swap factors are required for all aircraft types to be introduced to the fleet. Information on aircraft Original Equipment Manufacturer's (OEM) order backlogs build the basis for the determination of micro-swap

\begin{tabular}{|c|c|c|}
\hline \multicolumn{3}{|c|}{ Macro-swap factors } \\
\hline & Year 1 & Year 2 \\
\hline CT & $50 \%$ & $0 \%$ \\
\hline NT-1 & $50 \%$ & $100 \%$ \\
\hline NT-2 & $0 \%$ & $0 \%$ \\
\hline
\end{tabular}

\begin{tabular}{|c|c|c|c|}
\hline \multicolumn{3}{|c|}{ Swap matrix (Excerpt) } \\
\hline $\begin{array}{c}\text { A/C type } \\
\text { to be } \\
\text { replaced }\end{array}$ & $\begin{array}{c}\text { Replacement } \\
\text { A/C type }\end{array}$ & $\begin{array}{c}\text { Swap factor } \\
\text { year 1 }\end{array}$ & $\begin{array}{c}\text { Swap factor } \\
\text { year 2 }\end{array}$ \\
\hline \multirow{4}{*}{ A320 } & Type 1 & $16 \%$ & $0 \%$ \\
\cline { 2 - 4 } & Type 2 & $34 \%$ & $0 \%$ \\
\cline { 2 - 4 } & Type 3 & $4 \%$ & $8 \%$ \\
\cline { 2 - 4 } & Type 4 & $46 \%$ & $92 \%$ \\
\hline \multirow{3}{*}{ B737 } & Type 1 & $16 \%$ & $0 \%$ \\
\cline { 2 - 4 } & Type 2 & $34 \%$ & $0 \%$ \\
\cline { 2 - 4 } & Type 3 & $4 \%$ & $8 \%$ \\
\cline { 2 - 4 } & Type 4 & $46 \%$ & $92 \%$ \\
\hline \multirow{4}{*}{ A } & & \\
\hline & 1 & & \\
\hline
\end{tabular}

Figure 5. Approach to derive a swap matrix from micro-swap and macro-swap factors. Excerpt for two narrow-body aircraft types (exemplary numbers). 
factors ${ }^{13-15}$. As presented in Figure 5 on the bottom left, for every aircraft type to be introduced, the ordered transport capacity (in AS) is calculated from the corresponding amount of ordered aircraft in the backlog and the specific aircraft's seat capacity. For CT aircraft, only those aircraft types are considered for future introduction to the fleet that are still being significantly produced. For each aircraft type, micro-swap factors are subsequently derived as a share of the total ordered transport capacity. One set of micro-swap factors are determined per technology generation and tube category.

Thirdly, the swap matrix is determined from micro- and macro-swap factors. As represented in Figure 5 on the right, the first column of the swap matrix describes the aircraft types that are subject to retirement in future years. The second column lists all aircraft types available to be introduced for a particular aircraft type. Multiplication of the aircraft type-specific micro-factor and the corresponding year-specific macro-factor results in the swap factor. Thus, on the basis of AS, swap factors precisely define how one aircraft type is replaced by a mix of aircraft types for each future year.

One major advantage of the presented aircraft introduction module is the ability to consider rules of aircraft substitution on a yearly basis. This allows for the simulation of continuous fleet mix developments rather than disruptive changes. Another advantage of the concept is that for each aircraft type, aircraft introduction can be distributed across an infinite number of different aircraft types to enter the fleet in future years.

\section{G. Airport Capacity Module}

Generally, capacity constraints at airports strongly influence airport flight plans. While an airport's schedule may allow significant growth during specific times of the day, traffic growth during peak hours may not be feasible due to runway and/or terminal capacity limits. Whereas most effects resulting from airport capacity constraints are neglected by the FFDT, the airport capacity module considers one particular effect regarding capacity constraints relevant for airport noise assessments. The module shifts flight operations exceeding the hourly airport capacity to less frequented, neighboring hours of the original operation possibly shifting day-time operations to evening or nighttime operations.

The airport capacity module applies an algorithm to reallocate infeasible growth at peak times to nearby hours. For this purpose, maximum throughputs in movements per hour for the specific runway system of an airport are defined, e.g. based on information by the airport coordinator. The module limits the number of operations to the maximum amount of hourly movements aggregated for departure and arrival operations. Potential shifts of operations from day-time operations to evening- or nighttimes eventually affect the DEN-level as a result of metricbased noise penalties by adding $+5 \mathrm{~dB}$ for evening-time operations, and $+10 \mathrm{~dB}$ by night-time operations.

Figure 6 represents the algorithm that is used by the

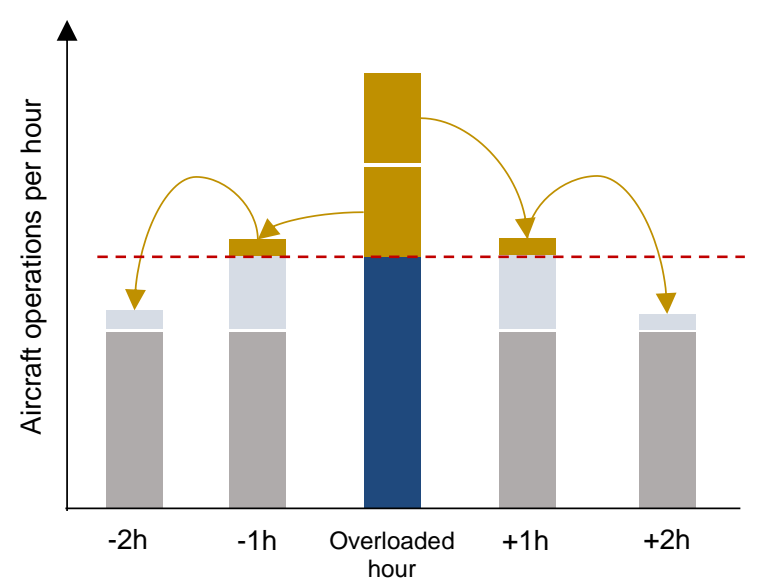

Figure 6. Method of operation of the airport capacity module. Operations exceeding the maximum hourly capacity are shifted to less frequented times of the day airport capacity module to reallocate aircraft operations exceeding the amount of maximum hourly movements to the next closest hours with free capacities. Overloaded hours in a future flight plan are reduced to the defined limit of maximum hourly movements. As depicted in Figure 6 excess movements are shifted to the closest possible hours. The airport capacity module of the FFDT does not account for additional effects resulting from capacity constraints, e.g. possible increases in average aircraft size caused by airports' capacity constraints.

\section{Aircraft Noise and Airport Noise Modeling}

The developed method FANAM includes the modeling of three different systems as visualized in Figure 1. Whereas the focus of this paper is on the development of the flight plan model, a brief overview on the current state of the two further modeling areas is given.

\section{A. Aircraft-Level Noise Modeling}

Modeling aircraft noise at the vehicle level is crucial to noise assessment studies at the airport level. At the same time, trade-offs must be made in terms of complexity and accuracy of the aircraft noise models, as not only a single 
aircraft type or a single operation is of interest, but a significant amount of aircraft types and a large amount of operations are relevant.

Modeling aircraft noise within FANAM is based on Aircraft Noise and Performance (ANP) models provided by Eurocontrol. ANP models contain aircraft information relevant to airport-level noise studies. For instance, in ANP models, relevant engine characteristics are defined by so-called jet/propeller engine coefficients. Aerodynamic aircraft characteristics are described by aerodynamic coefficients. Aircraft weights according to different stage lengths are defined by default weights. Approach and departure procedures are defined by default departure/arrival procedure steps. Aircraft noise characteristics are defined by noise-power-distance data (NPD Data). NPD data describe aircraft noise levels both for different distances between observer and sound source and for different aircraft thrust settings. ${ }^{16}$

ANP datasets are available for most aircraft in the current world fleet. These aircraft models will be integrated and applied by FANAM. More recent aircraft types, in particular NT-1 aircraft types, may not have ANP datasets available. To be able to assess impacts at the airport-level resulting from newer aircraft types, it is necessary to also include these aircraft into FANAM. For this, a surrogate-aircraft approach using available ANP datasets of CT aircraft types will be applied by the framework.

\section{B. Airport-Level Noise Modeling}

As proposed by Figure 1, modeled future flight plans and aircraft noise models will be used by FANAM to assess aircraft noise contours at the airport level. Modeling airport noise requires the consideration of the specific runway layout and of the specific arrival and departure routes of the airport under consideration. Furthermore, the airport noise model needs to consider atmospheric characteristics relevant to noise evaluations, such as temperature, pressure, headwind, and humidity. Noise emissions of single aircraft operations need to be combined to DEN-levels describing the noise situation of an entire day. For airport noise assessments, it is also important to define a suitable grid of noise receptors, that is, virtual microphones, in the airport noise model.

For airport noise assessments, FANAM will make use of the modeling capabilities of the Aviation Environmental Design Tool (AEDT). The AEDT is a comprehensive tool developed by the FAA to estimate environmental impacts by aviation. Principally, the AEDT combines several tools that assess different environmental aspects. The AEDT has replaced the FAA tools for local air quality (EDMS, Emissions and Dispersion Modeling System), for airport noise (INM), and for global noise (NIRS, Noise Integrated Routing System) ${ }^{17}$. However, FANAM only makes use of the AEDT's capabilities with respect to airport-level noise. Fundamental standards of AEDT regarding noise assessment are the ECAC.CEAC Doc 29 -Report on Standard Method of Computing Noise Contours around Civil Airports ${ }^{18}$ and the SAE AIR1845 - Procedure for the Calculation of Airplane Noise in the Vicinity of Airports ${ }^{19}$.

FANAM uses version $2 \mathrm{~b}$ of the AEDT. In order to include the AEDT into FANAM, a number of pre-processing steps are required. For example, a module is developed to convert a developed flight plan into an ASIF (AEDT Standard Input File) which is a .xml-file as used by the AEDT. In the same way, FANAM also includes postprocessing to evaluate airport-level noise results calculated using the AEDT.

\section{Application Case}

This chapter presents an application case of the FFDT to model future flight plans for different scenarios. Noise contours at airport level resulting from the overarching method FANAM (see Figure 1) are not assessed in this work. Whereas the presented results do not aim at modeling real future fleet mixes or flight plans, the application case serves as a demonstration of the general capabilities of the FFDT to reflect the impact of varying input parameters in the generation of future flight plans.

\section{A. Assumptions}

The following gives a brief summary of assumptions that are applied to all scenarios presented in Sections B and C. Scenario-specific characteristics are presented in the corresponding sections. The developed FFDT is applied to Munich Airport (ICAO code: EDDM). A Munich Airport flight plan from the year 2014 derived by OAG data serves as base flight plan for the development of future flight plans. In a first step, from OAG data a flight plan of equivalent noise events is derived according to Section B. In a second step, from the flight plan of equivalent noise events, future flight plans are developed for the study years 2030 and 2040 by applying the FFDT.

Within the FFDT the air traffic growth module (Section C) applies growth data as specified by the Airbus Global Market Forecast. For Munich Airport, the 20 relevant region-pairs including 'Western Europe' are applied within the FFDT. The aircraft retirement module is applied as specified in Section D, thus aircraft-specific retirement behavior is identical for all scenarios. The gap module is used as presented in Section E. For the introduction of new aircraft to the fleet the aircraft introduction module (see section F) considers the following CT aircraft types: For CT narrow- 
body aircraft Airbus A320ceo, Airbus A321ceo, and Boeing 737-800, for CT wide-body aircraft Airbus A330-200, Airbus A330-300, A380-800, Boeing 777-300ER, and Boeing 787-8. Concerning new technology generation aircraft it applies the following already noise-certified NT-1 types ${ }^{20}$ : For NT-1 narrow-body aircraft Bombardier CS-100, Bombardier CS-300, and Airbus A320neo, for NT-1 wide-body aircraft Airbus A350-900, Airbus A350-1000, and Boeing B787-9. Concerning macro-swap factors, thus, the share of CT, NT-1, and NT-2 aircraft entering the aircraft fleet, several introduction scenarios are applied, as described in Sections B and C. For the application of the capacity module (Section G), a maximum airport capacity of 120 operations per hour is considered which corresponds to Munich Airport's maximum aircraft throughput, assuming a potential future third runway.

\section{B. 2030 Scenarios}

For the year 2030, two different scenarios are assessed. As mentioned, the scenarios differ in the share of technology generation of new aircraft entering the fleet. In the Scenario Status Quo Case 2030, a gap in flight plan of a specific aircraft type is fully filled by the same aircraft type, in other words, an aircraft type is replaced by its own type. Consequently, only CT aircraft types, and no NT-1 aircraft types are introduced to the fleet for all future years. The Scenario Realistic Case 2030 attempts to represent a realistic introduction of new aircraft technology to the fleet. In the year 2015, the insertion of NT-1 aircraft types is assumed to start at a level as derived from publicly available aircraft OEMs' order books. According to the analysis of the order books, the macro-swap factor of NT-1 aircraft is set to $72.5 \%$ for wide-body aircraft and to $64 \%$ for narrow-body aircraft, CT swap factors are $27.5 \%$ and $36 \%$, respectively. In the year 2025, macro-swap factors of NT-1 aircraft are assumed to be $100 \%$, thus from 2025 on, only NT-1 aircraft enter the fleet. For the years between 2015 and 2025, macro-factors are kept constant with a half-step in 2020 (86.25\% for wide-bodies, $82 \%$ for narrow-bodies).

In Figure 7, exemplary results for the two scenarios are presented. From the flight plans derived by the FFDT, the total amount of daily operations is calculated for all years until 2030. Both scenarios experience an increase in flight operations as a result of assumed air traffic growth. However, the increase in flight operations varies according to the scenario introducing different mixes of new aircraft to the fleet.

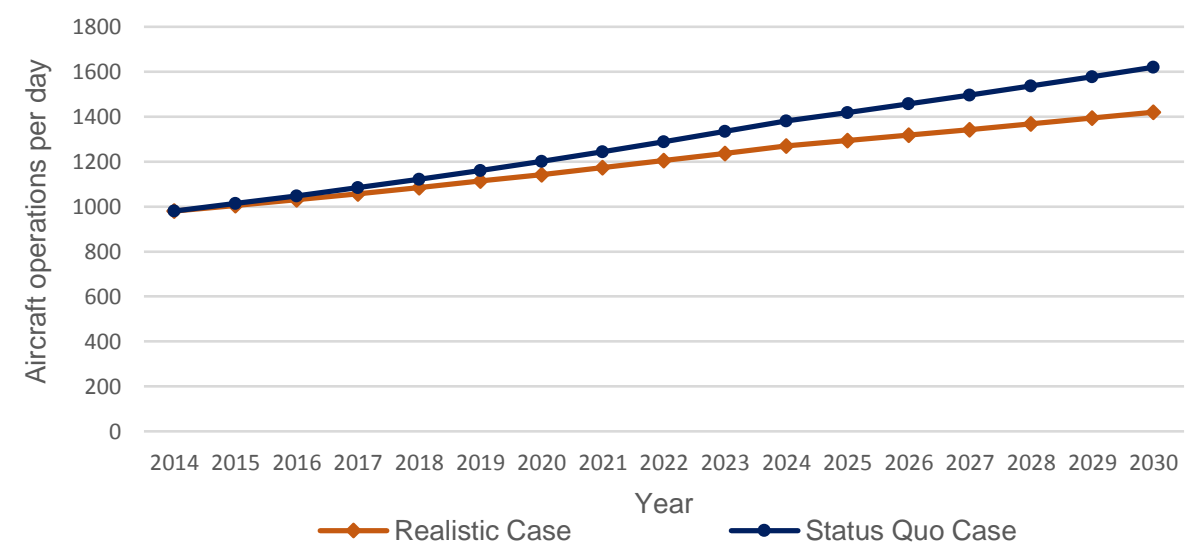

Figure 7. Exemplary Future Flight Plan Development Tool results: Amount of daily aircraft operations for two scenarios varying in technology generation (CT/NT-1) introduced to the fleet

Generally, a higher average aircraft size of new aircraft entering the fleet reduces the increase in the number of flight operations. Starting from an average aircraft size of 151.8 PAX/AC in the year 2014, until 2030 the average aircraft size increases to 173.6 PAX/AC in the Realistic Case 2030. The significant increase in average aircraft size is due to the assumed replacement of small regional aircraft operating at Munich Airport during the base year with larger NT-1 narrow-body aircraft, with the Bombardier CS-100 being the smallest aircraft type available for introduction (see Section A). In the Status Quo Case 2030, where an aircraft type is substituted by the identical type, average aircraft size remains almost equal at 152.3 PAX/AC until 2030. This case serves as comparison and is not realistic as it introduces aircraft types for future years that, in reality, are not produced any more. The slight increase in aircraft size compared to 2014 results from different air traffic growth for varying region routes. For example, higher growth rates for Asian regions lead to stronger growth of long-haul traffic and thereby to an increase in average aircraft size.

The application case hereby also demonstrates the FFDT's ability to reflect regional-specific growth rates on future flight plans and thus FANAM's ability to reflect regional-specific growth rates on airport noise contours. Furthermore, it presents FANAM's capabilities to independently process air traffic growth and growth in aircraft operations by treating the average aircraft size as a non-predetermined degree of freedom. 


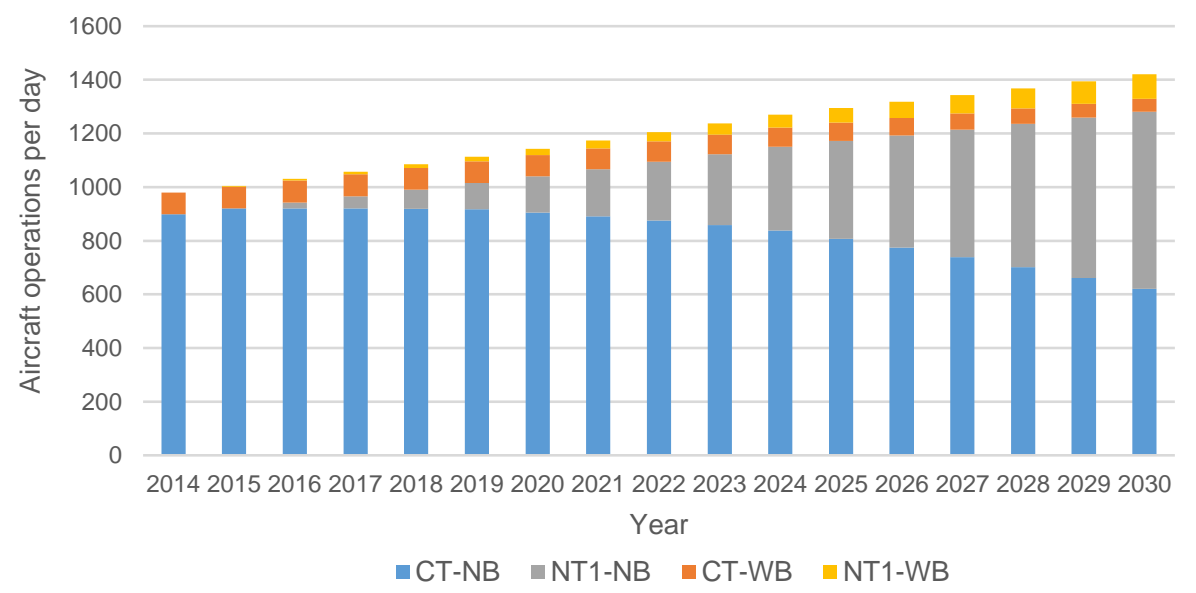

Figure 8. Exemplary Future Flight Plan Development Tool results for Realistic Case 2030: Share of aircraft operations by technology generation (CT/NT-1) and tube category (NB/WB)

In Figure 8, FFDT results from the Realistic Case 2030 are further detailed. The figure presents the share of aircraft operations on technology generation from 2014 to 2030 for both narrow-body and wide-body aircraft. With future years, the shares of CT aircraft types decrease for both narrow-body and wide-body aircraft while the shares of NT-1 aircraft increase as a result of new aircraft introduced to the fleet. Figure 8 also visualizes the FFDT's capabilities to develop fleet mixes and thus flight plans for future years in an evolutionary way.

\section{2040 Scenarios including NT-2 Technology}

The developed method FANAM is designed to also account for a reduction in noise emission in hypothetical future aircraft types belonging to technology generation NT-2. As with NT-1 aircraft, in order to assess the impact of noise emission reduction in NT-2 aircraft types at airport level, the aircraft's insertion into the aircraft fleet needs to be modeled.

The objective of the Futuristic Case 2040 is to evaluate the impact of a hypothetical noise-reduced NT-2 concept aircraft $N T 2-N B-160$, which is assumed to be a narrow-body aircraft with a capacity of 160 seats. In general, the Futuristic Case 2040 represents the continuation of the Realistic Case 2030 (see Section B). However, starting from 2031, the NT2-NB-160 is introduced to the fleet. The corresponding macro-swap factor of the NT-2 concept aircraft is set to $100 \%$, thus from 2031, for narrow-body aircraft no more NT-1 aircraft types are inserted into the fleet, only the NT-2 concept aircraft. For wide-body aircraft, NT-1 aircraft continue to be commissioned as a continuation of the Realistic Case 2030 scenario.

In Figure 9, results for the Futuristic Case 2040 are depicted. The share of aircraft operations on technology generation from 2030 to 2040 for both

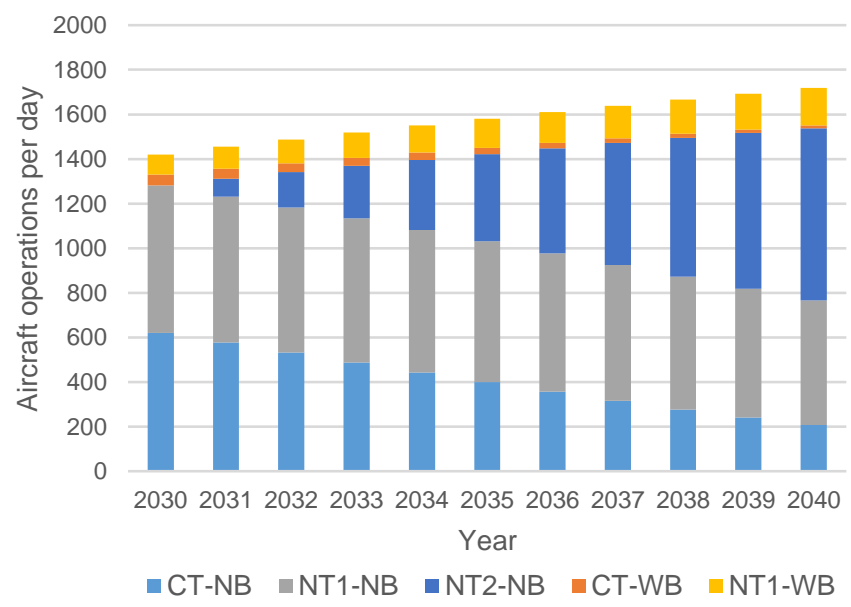

Figure 9. Exemplary FFDT results for Futuristic Case 2040: Share of aircraft operations by technology generation (CT/NT-1/NT-2) and tube category narrow-body and wide-body aircraft is presented. As shown, over time, the share of CT aircraft decreases for both the narrow-body and the wide-body segment as result of aircraft retirement. For the narrow-body aircraft segment, the share of NT-1 aircraft decreases as well. Simultaneously, the share of NT-2 aircraft strongly increases, as all narrowbody aircraft introduced to the fleet are of the type NT2-NB-160. For the wide-body segment, the share of NT-1 aircraft further increases since retired wide-body aircraft are still replaced by NT-1 aircraft types. 


\section{Conclusion}

We have developed a method to assess fundamental impacts on future airport-level noise situations. For this purpose, the created Future Airport Noise Impact Assessment Method (FANAM) models three main areas: Firstly, future flight plans, secondly, aircraft-level noise emissions, and thirdly, airport-level noise exposure. The method develops and uses the concept of Flight Plans of Equivalent Noise Events specifically tailored for airport-level noise studies.

The focus of the presented work lies on the development of the flight plan modeling capabilities realized with the Future Flight Plan Development Tool (FFDT). The individual modules of the FFDT implemented in MATLAB ${ }^{\circledR}$ are introduced. Finally, an application case applies the FFDT to Munich Airport deriving future flight plans for different scenarios with the time horizon 2030 and 2040. Whereas the application case does not attempt to forecast realistic flight plans for Munich Airport, it serves to verify the FFDT's capabilities to successfully model flight plans iteratively for future years. The application case also shows the FFDT's abilities to derive scenario-specific flight plans depending on varying user-defined scenario input. It is thus able to reflect changes in future developments, e.g. concerning air traffic growth or aircraft introduction, on future flight plans and thereby enables the overarching FANAM method to be used for impact assessments in airport-level noise studies.

As presented, the foundations of the developed method have been laid, however, further work is required prior to application of the method. The models need to be consolidated towards the overarching FANAM method. Furthermore, the developed approach will be subject to validation processes. Finally, aiming for relative comparisons between relevant scenarios, the method will find application by evaluating scenario-specific airport-level noise contours quantified through DEN-levels.

\section{References}

${ }^{1}$ Dobrzynski, W., "Almost 40 Years of Airframe Noise Research: What Did We Achieve?," Journal of Aircraft, Vol. 47, No. 2, 2010, pp. 353-367.

${ }^{2}$ Bertsch, L., Guérin, S., Looye, G., and Pott-Pollenske, M., "The Parametric Aircraft Noise Analysis Module status overview and recent applications," 17th AIAA/CEAS Aeroacoustics Conference.

${ }^{3}$ Thomas, R. H., Burley, C. L., and Nickol, C. L., "Assessment of the Noise Reduction Potential of Advanced Subsonic Transport Concepts for NASA's Environmentally Responsible Aviation Project," 54th AIAA Aerospace Sciences Meeting.

${ }^{4}$ Clarke, J.-P. B., Ho, N. T., Ren, L., Brown, J. A., Elmer, K. R., et al., "Continuous Descent Approach: Design and Flight Test for Louisville International Airport," Journal of Aircraft, Vol. 41, No. 5, 2004, pp. 1054-1066.

${ }^{5}$ Bundesministerium der Justiz und für Verbraucherschutz (Federal Ministry of Justice and Consumer Protection), "Gesetz zum Schutz gegen Fluglärm (Aircraft Noise Act)," 2007.

${ }^{6}$ Bernardo, J. E., Besson, C., Pfaender, H., Schutte, J., and Mavris, D. N., "A Multi-Stage Surrogate Modeling Approach to Examine Vehicle-Level Technology Impacts at the Airport-Level," 53rd AIAA Aerospace Sciences Meeting.

${ }^{7}$ Torija, A. J., Self, R. H., and Flindell, I. H., "A model for the rapid assessment of the impact of aviation noise near airports," The Journal of the Acoustical Society of America, Vol. 141, No. 2, 2017, p. 981.

${ }^{8}$ OAG Worldwide Limited, "Official Airline Guide Schedules Data 2014,".

${ }^{9}$ Airbus S.A.S., "Airbus Global Market Forecast 2016-2035," URL:

http://www.airbus.com/company/market/global-market-forecast-2016-2035/ [cited 20 October 2016].

${ }^{10}$ Randt, N. P., "Aircraft Technology Assessment Using Fleet-Level Metrics," Ph.D. Dissertation, Technical University of Munich, 2016.

${ }^{11}$ International Civil Aviation Organization, "CAEP-SG/20082-IP/02: Forecasting and Economic Analysis Support Group (FESG),” 2008, URL: http://s3.amazonaws.com/zanran_storage/www.icao.int/ContentPages/108603156.pdf [cited 26 October 2016].

${ }^{12}$ Airlinerlist.com, “Airlinerlist,” URL: http://airlinerlist.com/ [cited 22 October 2016].

${ }^{13}$ Airbus, "Orders \& Deliveries," 2016, URL: http://www.airbus.com/company/market/orders-deliveries/ [cited 29 October 2016].

${ }^{14}$ Boeing, "Orders \& Deliveries," 2016, URL: http://www.boeing.com/commercial/\#/orders-deliveries [cited 29 October 2016].

${ }^{15}$ Bombardier, "Commercial Aircraft Status Reports," 2016, URL:

http://www.bombardier.com/en/media/commercial-aircraft-status-reports.html [cited 29 October 2016].

${ }^{16}$ Eurocontrol, "The Aircraft Noise and Performance (ANP) Database," URL:

https://www.aircraftnoisemodel.org/ [cited 19 April 2017]. 
${ }^{17}$ Koopmann, J., Zubrow, A., Hansen, A., Hwang, S., Ahearn, M., et al., “Aviation Environmental Design Tool (AEDT) 2b User Guide," 2016.

${ }^{18}$ European Civil Aviation Conference, "Report on Standard Method of Computing Noise Contours around Civil Airports: Report on Standard Method of Computing Noise Contours around Civil Airports,” ECAC.CEAC Doc 29, December 2005.

${ }^{19}$ Society of Automotive Engineers, "Procedure for the Calculation of Airplane Noise in the Vicinity of Airports," SAE AIR 1845, March 1986.

${ }^{20}$ European Aviation Safety Agency, “Type Certificates (TCDS),” URL: https://www.easa.europa.eu/documentlibrary/type-certificates [cited 25 October 2016]. 